\title{
Scientific justification of the formula composition of biotechnological form of BAA with directed functional properties
}

\author{
O. N. Bulashko ${ }^{1}, T$. V. Kotova ${ }^{1,2, *}$, and $V . M$. Poznyakovsky ${ }^{1,2}$ \\ ${ }^{1}$ Ural State University of Economics, 620144 Ekaterinburg, Russian Federation \\ ${ }^{2}$ Kemerovo State Medical University, 650029 Kemerovo, Russian Federation
}

\begin{abstract}
For the prevention and treatment of gastrointestinal diseases, the microbiome of the living organism is of great importance. The human health depends on quantitative and qualitative composition of microbiota. Under the influence of factors of internal and external environment there is a change in the indigenous microflora. For correction, prevention and regulation of intestinal microbiocenosis within the framework of the biotechnology program, biologically active additive (BAA) is proposed, the main components of which are selective biomass bacteria, prebiotics, peptide ultralisates. As substances that perform the function of coenzymes, thiamine (vitamin B1) and pyridoxine (vitamin B6) are used in the production of this additive. The novelty of the technology is the composition and structure of solid gelatin capsules, ensuring maximum safety of biologically active ingredients and delivery of them to cells. Regulated quality indicators have been established. Sanitary-hygienic and sanitary-toxicological indicators of the BAA comply with the requirements of TR CU 021/2011 "On safety of food products". Clinical approbation of the developed additive was carried out by volunteers with detected disorders of intestinal microbiota. BAA was taken 1 capsule 2 times a day in conjunction with other drugs regulating bowel biocenosis. At the end of dietary therapy, the microbiota recovery was observed in $90 \%$ of cases. Technical documentation has been approved for the new product, recommendations for application have been developed.
\end{abstract}

\section{Introduction}

The microbiome is of great importance in the processes of the organism's functioning. Modern biotechnology and nutritionology, the possibilities of using biotechnological products (pro-, pre- and metabiotics) play a major role for the prevention and comprehensive treatment of gastrointestinal diseases. Synbiotics (combinations of pre- and probiotics) are actively applied [1-3].

A promising way in the prevention, correction and regulation of intestinal microbiocenosis is the use of prebiotics of non-microbial origin that stimulate the growth of normal microflora. At the same time, they themselves do not participate in the metabolism

*Corresponding author: t_kotova@inbox.ru 
processes of the organism [4, 8]. This group includes dietary fibers (cellulose, inulin, hemicellulose, pectins), oligosaccharides of various origins, poly- and oligofructans, other numerous substances and compounds produced by biotechnological and chemical synthesis. Prebiotics are sources of available microflora carbohydrates as the main nutrient material $[5,7]$. One such prebiotic is inulin, in enzymatic decay of which short-chain fatty acids are formed, providing the bowel microbiota with energy and protecting it from inflammatory processes $[9,10]$.

\section{Object and research methods}

Living microcapsulated forms of probiotics (bifido- and lactobacilli), prebiotics and production samples of BAA, representing the biotechnology program correction of indigenic bowel microflora were used as subjects of the research.

Public and special methods of testing the quality and safety of the BAA were applied in accordance with the requirements of the regulatory documents to this group of specialized products. Bifidobacteria, lactobacteria, yeast and mold were determined by GOST 10444.11-2013, coliforms - GOST 31747-2012, pathogenic, including salmonella - GOST 31659-2012.

The method of determining $\beta$-glucans in specialized products of microbiological origin is based on their enzymatic hydrolysis using $\beta$-glucosidase (glucan-1.3- $\beta$-glucosidase) and $\alpha$ - glucosidase (glucan-1.4- $\alpha$-glucosidase). The product of enzymatic hydrolysis is determined by colorimetric method according to the degree of glucose coloration (GOST R 57513-2017).

\section{Results and discussion}

Within the framework of the biotechnology program, a new form of BAA has been developed to form and support own intestinal microflora. To substantiate the qualitative and quantitative composition of the BAA, the characteristic of formula ingredients is given, based on the available data on their use in experimental and clinical practice ( selective biomass bacteria, peptide ultralisates, prebiotics, vitamins and other components and auxiliary ingredients).

Dry selective biomass of bacteria:

- Bifidobacterium bifidum - used as a starter culture. The genetic feature of the strain is resistance to antibiotics, streptomycin, monomycin, zentamycin, and kanamycin. Has antagonitic activity in relation to enteropathogenic E. coli, Zonne and Flexner schigellas;

- Bifidobacterium infantis isolated from the intestines of a healthy child of the first year of life. Good acid-forming agent, inhibits opportunistic microorganisms, has resistance to a number of antibiotics, gastric juice and bile, normalizes the microflora of the gastrointestinal tract. Reduces the production of endotoxins, which are released when the bacterial cell decays (lysis), enter the bloodstream and cause metabolic endotoxemia. The latter leads to systemic inflammation of the intestines, provokes the development of other diseases;

- Bifidobacterium longum - positive properties manifest in the ability to regulate differentiated formation of anti-inflammatory cytotoxins and T-heliers Th2. It forms a humoral immune response by activating B-lymphocytes and inducing Th2-cytotoxin IL-10. This effect is carried out by living microbial cells in the form of filtrates, as well as their structural components - DNA, peptidoglycans and lipoteichoic acid;

- Bifidobacterium breve - isolated from the vagina of a healthy woman of reproductive age. Newborns acquire this type of flora from their mother, following pelvigenital canals. 
Actively suppresses the growth of opportunistic microorganisms - Pseudomonas aeruginosa, Escherichia coli, Streptococcus faecalis, Klebsiella ozaenae and Streptococcus aureus, increases the content of lactobacilli and bifidobacteria, thereby providing correction of dysbiotic disorders of the microbiota, dominant position of lactic acid bacteria and positive changes in microflora in general;

- Hactobacillus casei - is derived from Italian cheese, characterized by high life in storage. It is used as a ferment for dairy products. Normalizes intestinal microflora;

- Hactobacillus rhamnosus - used as probiotic; strain produces lactic acid, has great avidity for intestinal cells; resistant to acids and alkalis;

- Hactobacillus acidophilis - ferments mannite, glucose, maltose, lactose and sucrose, is used in the technology of baby milk products. Unlike known acidophilic strains has high proteoletic activity, is not exposed to phages, has a low limit of acid formation (limit acidity of the strain is $50^{\circ} \mathrm{T}$ ). Oppresses staphylococci, enterococci, spore forms of bacteria, normalizes intestinal microflora.

Prebiotics:

- inulin - belongs to a group of dietary fibers (polysaccharides). Not digested by digestive enzymes;

- fibrigum B - exudate of dietary fibers derived from acacia resin (Heguminosae);

- lactulose - inhibits the formation of potentially pathogenic bacteria, activates the growth of beneficial microorganisms (lacto-, bifidobacteria, etc.), providing a favorable balance of intestinal microflora. Lactulose, in an unchanged form, reaches the colon and is metabolized by its bacteria. Metabolism products shift the $\mathrm{pH}$ of the medium to a sour side, which is detrimental to the development of pathogenic microflora.

Metabiotic $\beta$-glucan has effective immunomodulatory properties. It is necessary for various diseases and pathological conditions of the body, has antitumoral and radioprotective effects.

Ultralizates peptide (products of splitting probiotic bacterial cells into fragments of the cell wall of bacteria and their intracellular contents):

- Propinibacterium freudereichii - probiotic isolated from Swiss cheese, used to protect agricultural raw materials and food products from microbial spoilage. It is a producer of acetic, propionic acids and cyanocabalamine (vitamin B12);

- Propinibacterium arabinosum - a producer of trehalose, propionic acid and cyanocabalamine. Propionic acid implements blocking the adhesion of pathogens to the intestinal epithelium, regulation of its proliferation and differentiation with energy supply. Provides substrates for gluconeogenesis, supports ion metabolism, has antibacterial effect, reduces saturated fatty acids content in blood and liver plasma, increases sensitivity to insulin. Vitamin B12 has high biological activity entering numerous enzymes as a cofactor, participates in erythrocyte maturation processes and hematopoiesis, reduces the concentration of "bad" cholesterol in blood, is a necessary component of nucleic acid biosynthesis and functioning of the nervous system. Trehalose performs a protective intracellular role when the stress occurs when the body is exposed to numerous factors of the internal and external environment.

Tiamine (vitamin B1) and pyridoxine (vitamin B6) are important as auxiliaries. By performing the function of coenzymes, they are involved in numerous metabolic processes of the body, necessary for normal growth and development of intestinal microflora.

Formula composition in the form of capsulated BAA form has been developed, the components of which have synergistic properties with respect to the support of the indigent microflora of the intestine (Table 1). 
Table 1. Formula of biologically active additive.

\begin{tabular}{|c|c|}
\hline Component name & $\begin{array}{c}\text { Content, mg/1 } \\
\text { capsule }\end{array}$ \\
\hline $\begin{array}{l}\text { Biomass bacteria selective dry BB-Bf series "Panbiom" } \\
\text { Bifidobacterium bifidum }\end{array}$ & 60 \\
\hline $\begin{array}{l}\text { Biomass of bacteria selective dry } \\
\text { Bifidobacterium infantis }\end{array}$ & 50 \\
\hline $\begin{array}{l}\text { Biomass bacteria selective dry BB-Ln series "Panbiom" } \\
\text { Bifidobacterium longum }\end{array}$ & 30 \\
\hline Biomass of bacteria selective dry BB-Br series "Panbiom" Bifidobacterium breve & 30 \\
\hline Biomass bacteria selective dry LB-Cs series "Panbiom" Lactobacillus casei & 60 \\
\hline $\begin{array}{l}\text { Biomass bacteria selective dry LB-Rm series "Panbiom" } \\
\text { Lactobacillus rhamnosus }\end{array}$ & 50 \\
\hline $\begin{array}{l}\text { Biomass bacteria selective dry LB-Ac series "Panbiom" } \\
\text { Lactobacillus acidophilus }\end{array}$ & 50 \\
\hline $\begin{array}{l}\text { Inulin Fibrulin Instant } \\
\text { Inulin }\end{array}$ & 13.897 \\
\hline$\beta$-glucan, $75 \%$ & 20 \\
\hline$\beta$-glucan & 15 \\
\hline Fibrigham B & 5 \\
\hline Lactulose semiproduct & 5 \\
\hline $\begin{array}{l}\text { Ultralizate peptide PR-Frd } \\
\text { Propionibacterium freudenreichii }\end{array}$ & 3 \\
\hline $\begin{array}{l}\text { Ultralizate peptide PR- } \\
\text { Propionibacterium arabinosum }\end{array}$ & 3 \\
\hline
\end{tabular}

As auxiliary substances in production technology are used: talc (anti-caking agent) - 12, calcium stearate (anti-caking agent) - 4, neosyl GP-4, pyridoxine hydrochloride - 0.058, thiamine hydrochloride -0.045 , gelatinous capsule -76 .

Production technology of capsulated form of BAA includes preparation of raw materials, which are ground at the hammer mill and sifted through a sieve with $1 \mathrm{~mm}$ cells. The finished substances are loaded into a $\mathrm{V}$-shaped mixer for the preparation of the mixture for capsulation at a rate of $100 \mathrm{~kg}-1$ hour. Capsulation process is carried out on a semiautomatic capsule machine. The mixture is priorly examined in a testing production laboratory, stored for no more than 15 days. Ready-made capsules are checked to meet the specified requirements for mass and appearance. Filling and packing is carried out according to the requirements of technical conditions for the developed product.

The innovation of the technology lies in the peculiarities of composition and structure of solid gelatin capsules, providing maximum preservation of biologically active ingredients and their targeted, step-by-step delivery to target cells.

Live microcapsulated bifido and lactobacilli are used as probiotics. The prebiotics that provide growth and viability of probiotics are fibrigum, lactulose and metabiotic $\beta$-glucan.

Organoleptic, physico-chemical and microbiological studies have been carried out after 15 months of storage of the finished product at $2-6^{\circ} \mathrm{C}$ and relative humidity not more than $60 \%$. Regulated quality indicators are established (Table 2 ). 
Table 2. Regulated indicators of BAA quality

\begin{tabular}{|l|c|}
\hline \multicolumn{1}{|c|}{ Indicator name } & Content of the characteristic \\
\hline Appearance & gelatin capsule \\
\hline Capsule content color & powder from white to cream color, insertions are admissible \\
\hline Smell and taste & peculiar \\
\hline Average capsule mass, $\mathrm{mg}$ & $476(428-523)$ \\
\hline Content, in 1 capsule & $15(12-18)$ \\
\hline
\end{tabular}

Content in 1 capsule: bifidobacterium - not less than $5000000000, \mathrm{CFU} / \mathrm{g}$; lactobacterium - not less than 5000000 000, CFU/g.

The evaluation of safety criteria was carried out in accordance with the requirements of TR CU 021/2011 "On food safety". The results are presented in Table 3, 4.

Table 3. Sanitary and hygienic indicators of BAA

\begin{tabular}{|c|c|c|c|}
\hline \multirow{2}{*}{\multicolumn{2}{|c|}{ Indicator name }} & \multicolumn{2}{|c|}{ Value of indicator } \\
\hline & & $\begin{array}{c}\text { acceptable } \\
\text { level }\end{array}$ & $\begin{array}{c}\text { actual } \\
\text { content }\end{array}$ \\
\hline \multicolumn{2}{|c|}{ Yeast, $\mathrm{CFU} / \mathrm{g}$, no more } & 100 & $\begin{array}{c}\text { less than } \\
10\end{array}$ \\
\hline \multicolumn{2}{|c|}{ Mold, $\mathrm{COE} / \mathrm{g}$, no more } & 100 & $\begin{array}{c}\text { less than } \\
10\end{array}$ \\
\hline \multirow{4}{*}{$\begin{array}{l}\text { Weight of the } \\
\text { product, g, in } \\
\text { which } \\
\text { are not allowed: }\end{array}$} & E. Coli & 1.0 & $\begin{array}{c}\text { not } \\
\text { found }\end{array}$ \\
\hline & Staphylococcus aureus & 2.0 & $\begin{array}{c}\text { not } \\
\text { found }\end{array}$ \\
\hline & Pathogenic including salmonella & 10.0 & $\begin{array}{c}\text { not } \\
\text { found }\end{array}$ \\
\hline & coliforms & 0.1 & $\begin{array}{l}\text { not } \\
\text { found }\end{array}$ \\
\hline
\end{tabular}

Table 4. Sanitary and toxicological indicators of BAA

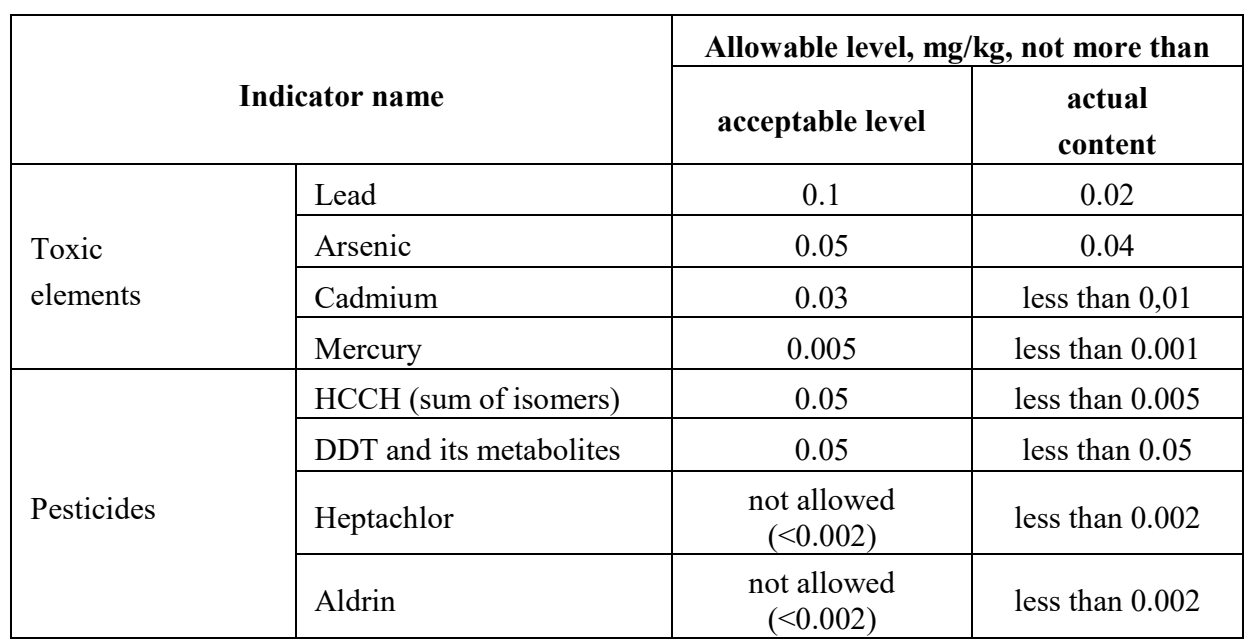


The obtained data show that the test safety indicators comply with established standards, which allows to determine the permissible shelf life - 1 year with a "safety margin" - 3 months under the above conditions.

Clinical approbation of the developed product was carried out by prescribing it to 60 volunteers aged 33-72 years who had detected disorders of the intestinal microbiota: reducing the number of normal symbiotes (bifido-, lactobacilli, Escherichia coli (Lac +) presence of pathogenic microbes (Klebsiella pnenmoniae, fungi of the genus Candida alticans). BAA was taken 1 capsule 2 times a day (in the morning 30 minutes before meal and in the evening before bedtime) in conjunction with other medications regulating bowel biocenosis. Course of administration is 30 days.

At the end of dietary therapy, the recovery of microbiota in $90 \%$ of cases was observed, complaints about manifestations of local intestinal syndrome - chair disturbance, flatulence, pain of various nature, etc., disappeared, improved the overall condition of the organism.

\section{Conclusion}

Based on the obtained material and the conclusion of Rospotrebnadzor, BAA biotechnology pro-gram can be used as an effective preventive means of bowel endogenous microflora support, preventing dyspepsis disorders and increasing immunity.

Technical documentation has been approved for the new product, recommendations for use are developed for 1 capsule once a day during meals. It is produced at the enterprises of the company "Art Life" (Tomsk), the guarantee of quality, safety and demand in the market are provided by the implementation of international and national standards, the inclusion of the BAA in the Federal Register.

\section{References}

1. I. Mechnikov, Etudes of optimism6 253 (M.: The main edition of literature in foreign languages of the publishing house "Science", 1988)

2. D. Sonnenburg, E. Sonnenburg, Healthy Intestines. How to gain control over weight, mood and well-being, trans. from English E. Kupriano-howl (M .: Mann, Ivanov and Ferber, 2019).

3. Button Bozena, Your second brain is the intestines. Compass book on the invisible connections of our body, trans. with the floor. N. Zharska, 272 (M .: Eksmo, 2019)

4. I. Yu. Chicherin, I. P. Pogorelsky, I. A. Lundowski, I.V. Darmov, M.R. Shabalina, A.N. Podvolotsky, Infectious diseases, 14, 3, S. 37-48 (2016)

5. M. G. H. Besselink, H. C. van Santvoort, E. Buskens, M. A. Boermeesteret al., Lancet,; 371, 651-659 (2008)

6. B. U. Rudwan, C. J. M. Koning, M. G. H. H. Besselink, H. M. Timmermanet al. Lettersin Applied Microbiology, 46, 61-67 (2008)

7. I. Yu. Chicherin, IP Pogorelsky, I. A. Lundovskikh, N. V. Pozolotina, K. E. Gavrilov, I. V. Darmov, M. R. Shabalina, Infectious diseases, 13, 4, 43-52 (2015)

8. I. Yu. Chicherin, I. P. Pogorelsky, I. A. Lundovsky, N. V. Pozolotina, I. V. Darmov, K. E. Gavrilov, A. S. Gorshkov, A. I. Manshin, Journal of International Medicine, 2 (19), 24-31 (2016)

9. Satellite Symposium «New approaches to the therapy of diseases of the gastrointestinal system», 3, 77 (2011)

10. I. Y. Chicherin, Experimental and Clinical Gastroenterology, 7, 106 (2016) 